\title{
Ambulatory Assessment of Skin Conductivity During First Thesis Presentation: Lower Self-Confidence Predicts Prolonged Stress Response
}

\author{
Achim Elfering - Simone Grebner
}

Published online: 9 March 2011

(C) Springer Science+Business Media, LLC 2011

\begin{abstract}
In this field study self-confidence was tested to predict the course of galvanic electrodermal stress response prior, during and after public speaking. Ten graduate students initially rated their self-confidence and afterwards presented their thesis proposals orally in a 10-min presentation to their supervisor and peers. Galvanic skin response level was measured throughout and analysed for $10 \mathrm{~min}$ prior to, during, and $10 \mathrm{~min}$ after the presentation. Two major galvanic electrodermal stress response types were observed. Five students showed a 'healthy response', i.e. an anticipatory increase in electrodermal conductance, followed by a decrease after termination of the presentation. The other five students showed a steady increase of skin conductance during and after their presentation ('prolonged response'). In line with the allostatic load model the 'prolonged response' group reported significantly lower self-confidence before presentation than the 'healthy response' group $(p<0.01)$. Self-confidence is a resource in novices facing an unfamiliar stressor.
\end{abstract}

Keywords Galvanic stress response - Self-confidence · Public speaking

\footnotetext{
A. Elfering $(\bowtie)$

Department of Psychology, University of Berne,

Muesmattstrasse 45, CH-3000, Berne 9, Switzerland

e-mail: achim.elfering@psy.unibe.ch

S. Grebner

University of Applied Sciences Northwestern Switzerland, School of Applied Psychology, Riggenbachstrasse 16, CH-4600, Olten, Switzerland
}

\section{Introduction}

Public speaking is stressful and increases physiological arousal as part of the stress response. For instance, oral defence of one's master thesis proposal to one's supervisor and peers is stressful for most graduate students (Bachmann et al. 1999; Croft et al. 2004; Gilkinson 1942). Moreover, anticipation of public speaking causes stress in most individuals (Boucsein and Wendt-Suhl 1981; Kirschbaum et al. 1993). Anticipation of public speaking and public speaking itself induce ego-threat and a shift of attention focus towards the self (Kallus 1992). Self-confidence as a personal resource helps one to focus on the task and to recover quickly after the presentation (Semmer et al. 2007). Therefore, greater self-confidence should be related to a 'healthy response' to the stressor (McEwen 1998). A healthy response includes increasing activation prior to the talk, high activation during the talk in order to cope actively with the stressor and decreasing activation after the talk has ended in terms of physiological recovery. Conversely, lower self-confidence should be related to a 'prolonged response', i.e. a sustained or even increasing activation after the talk has ended (McEwen 1998) owing to perseverative cognition (Brosschot et al. 2005), for instance in terms of rumination about one's performance level.

Defence of Master Thesis and Skin Conductivity

Skin conductivity is affected by the sweat from physical activity and by emotional stimuli (Boucsein 1992). Skin conductivity rises with activation of the sympathetic nervous system (SNS). Galvanic skin response (GSR) represents electrical conductivity between two points on the respondent's skin. In their review, Backs and Boucsein 
(2000) report GSR to be the most convenient physiological indicator for workload: 'GSR amplitudes may reflect the amount of affective or emotional arousal elicited by a stimulus or a situation' (p. 15). Moreover, the recovery of GSR has been demonstrated to be a sensitive indicator of mental strain (Boucsein 1992). Hence, Fahrenberg and Wientjes (2000) report skin conductivity to be among the most suitable measures of arousal in field studies. Nevertheless, screening of the bibliography of ambulatory assessment of Fahrenberg (2006) and elaborated bibliographies from the society of ambulatory assessment (www.ambulatory-assessment.org) reveal only a few studies that have used continuous ambulatory assessment of GSR in field studies (Simpson and Turpin 1983; Turpin et al. 1983; White and Charles 1983).

In the defence of one's master thesis proposal, skin conductance level is expected to increase before the oral defence starts in terms of an anticipatory response. In addition, during the proposal defence students are expected to show increased skin conductance levels in terms of a response to the public speaking situation. After termination of the defence, physiological recovery should take place. Therefore, after the thesis proposal defence has ended GSR should return to lower levels to indicate a healthy response. When GSR remains high after the public speaking situation has ended, physiological recovery does not take place. Prolonged elevated levels of GSR indicate prolonged activation of the SNS after the thesis proposal defence has ended (Croft et al. 2004). In terms of the allostatic load model (McEwen 1998) the 'prolonged response' is characterised by a lack of physiological recovery after stressor termination (also known as lack of physiological unwinding, cf. Frankenhaeuser 1991).

\section{Prediction of Response Pattern}

Individuals high in self-confidence are expected to perform better in complex and novel tasks, because they are less likely to shift their attention focus towards the self (Kallus 1992). Therefore, they engage less in task-irrelevant cognitions (e.g. telling themselves that their performance is not sufficient) and focus more on task-relevant aspects (e.g. giving an adequate answer to a question posed by the supervisor). Self-confidence as a personal resource helps one to focus on the task because individuals who are more self-confident are also more confident about coping successfully with novel tasks because they believe in their abilities rather more (Judge et al. 2000). We expect that self-confidence measured shortly before one has to give a presentation has conceptual overlap with task-related selfesteem and self-efficacy. Self-efficacy refers to the belief of being able to mobilise the skills that are necessary to attain a given goal (Bandura 1997). Self-efficacy indicates that one is able to perform in an effective way. Individuals with high self-confidence therefore should recover more quickly after their first public presentation of their thesis because they think less about possible shortcomings, flaws and imperfections. We expect greater self-confidence to be associated with normal stress response whereas lower selfconfidence should be associated with prolonged stress responses.

\section{Hypotheses}

We expect high self-confidence measured before students start their oral thesis defence to predict healthy skin conductance response, whereas lower self-confidence should predict a prolonged skin conductance response after termination of the oral defence.

\section{Method}

\section{Sample}

Twelve participants of a graduate seminar on methods in industrial/organisational psychology volunteered to participate. All participants gave their informed consent prior to their inclusion in the study. The first six participants presented in the first session while the other participants were absent. The other six participants presented the next session while the first six participants were absent. One presentation in the first session was skipped because of shortage of time. Another presentation in the second session ended with the session so that the 10 -min recovery period was lost. Therefore, complete data were available for ten out of twelve participants (eight female and two male psychology majors, mean age $=26.1$ years, $S D=2.7$ years )

\section{Procedure}

Starting at 4.15 p.m. on two consecutive Tuesdays six participants each defended their master's thesis proposals orally by giving a PowerPoint presentation to their supervisor, another faculty and peer students who were participants of the course. During the presentation the supervisors asked questions, and made comments and suggestions in terms of feedback. Students were also instructed to ask supervisors for advice with regard to unclear aspects. The focus of the thesis proposal defence was on the study hypotheses and their rationale. Presentations were limited to $10 \mathrm{~min}$. 


\section{Talk Performance}

All master students had the goal of presenting their first version of a hypothesis from the research question. During the presentation a record clerk made a protocol of all supervisor comments on the slides of the presentation. The protocol was the basis for a goal attainment rating. The goal attainment was rated according to the following rating scheme (zero points $=$ staying at the level of the research question without deriving a hypothesis). If there was a deduction of hypotheses from the research question, the following yes/no criteria were tested:

(1) was the hypothesis clearly linked to the research question?

(2) was the hypothesis consistent (without inherent contradiction)?

(3) were the hypotheses formulated on a concrete construct level (operationalisation)?

(4) was the hypothesis as specific as possible (e.g. directional where appropriate and not non-directional)?

(5) did the hypothesis correctly include only one assumption (no mix of assumptions like 'men make fewer errors and perform quicker than women')?

(6) does the hypothesis correctly state what was intended with respect to processes (e.g. hypothesis describing a moderation effect where a mediation effect was intended to be described)?

(7) was an incorrectly existential hypothesis formulated where a difference or association between groups was expected ('There are men who perform better than women' instead of 'men perform better than women') ?

(8) was the null hypothesis treated like an alternative hypothesis? (e.g. when intending to replicate a test of hypotheses from a former work that rejected the alternative hypothesis, students tend to write 'expect no difference between...', i.e. to replicate the finding instead of the hypothesis test.

All criteria were accorded one point. Performance was calculated as the sum of points (range $0-8$ ).

\section{Self-confidence}

Situational well-being was assessed before the lesson started at approx. 4.15 p.m. Participants filled in the selfconfidence scale of Apenburg's questionnaire (EZ-36, 1986). The scale consisted of five items ('certain', 'sophisticated', 'confident', 'superior', 'experienced') that were averaged to form the scale. Participants were asked how adequate the items describe their current condition. Items were six-point Likert-scaled $(1=$ item does not represent my condition to $6=$ item does fully represent my condition). Higher scores of the scale represent more favourable self confidence. An overview of psychometric properties of the scale reports satisfying reliability (inner consistency is higher than .80, Schütte 2009).

In this study, the internal consistency of the scale was satisfactory (Cronbach's alpha was 0.73). Schütte (2009) reports good validity when the scale is used in work design studies.

\section{Electrodermal Skin Conductance}

Galvanic skin response was measured continuously (Boucsein et al. 2001) with the BodyMedia Body SenseWear bracelet. The bracelet is a continuous monitoring system and comprises a unit that is attached to the back of the upper arm by an elastic Velcro strap. The small unit contains several sensors including accelerometer, heat flux, galvanic skin response and both skin and near-body temperature sensors. Galvanic skin response is used as an indicator of sympathetic nervous system activation and is measured by means of two hypoallergenic stainless steel electrodes (Boucsein 2005). The unit of measurement is microsiemens. Recovery time constants of skin conductance level are 15-30 s (Boucsein 2001). Until now, there is a lack of validity studies on GSR measured with the SenseWear bracelet. Lee et al. (2007) found GSR measured with the SenseWear device not to be affected by skin temperature.

In order to cover recovery of GSR before, during, and after the end of presentation minute-based GSR data were averaged in six $5 \mathrm{~min}$ windows, covering two periods before, two during, and two blocks after the thesis proposal defence ended.

\section{Statistical Analyses}

All statistics were nonparametric. Correlations were based on Kendall's tau (1955). A nonparametric trend test for correlated data (Ferguson 1965) was used to test for monotone, bitone, and tritone trend components in the SCL responses. The trend test for correlated data by Ferguson (1965) makes use of the statistic S, as used by Kendall (1955). The trend test included six consecutive measurements of SCL, each comprising a time window of $5 \mathrm{~min}$. Of the six 5-min intervals, interval 1 and interval 2 preceded the start of the presentation, covering the 10-min period before the thesis presentation started. Interval 3 and interval 4 covered the $10 \mathrm{~min}$ during the presentation and interval 5 and interval 6 covered the 10 -min period after the thesis presentation ended.

\section{Results}

Rank correlations showed significant positive associations between 5-min blocks of SCL measurement intervals 
(Table 1). There were no significant associations between 5-min measures of SCL level and self-confidence, Talk performance scored zero points in five participants because they failed to present hypotheses at all but stayed on the more general level of the research question. The other participants scored four points (one participant), six points (three participants), and seven points (one participant). Performance tended to be slightly better in women than men, but this difference was not significant. All correlations between study variables and performance were not statistically meaningful.

Identification of Response Pattern

The normal/prolonged SCL response pattern was tested with nonparametric trend analyses (Ferguson 1965). The normal SCL response pattern was represented by five participants showing the bitone course of SCL of an increase before the presentations started, and a decrease after the presentations finished (Fig. 1). The prolonged response pattern was represented by five participants showing a monotone increase of SCL across the six 5-min SCL blocks. Accordingly, the trend analysis (Table 2) confirmed significant first-order and second-order trend components $(z=4.352, \quad p<0.001$, and $z=-2.458, \quad p=0.014$, respectively). A separate trend analysis for the groups of five participants each representing the normal versus prolonged response pattern group revealed a significant monotone trend component in the prolonged activation group $(z=4.700, p<0.001)$, whereas the bitone trend component was absent $(z=0.000, p=1)$. The reverse pattern appeared for the normal response group. The normal response was characterised by a non-significant monotone trend component $(z=1.354, p=0.177)$, but a significant bitone trend component $(z=-3.487, p<0.001)$.

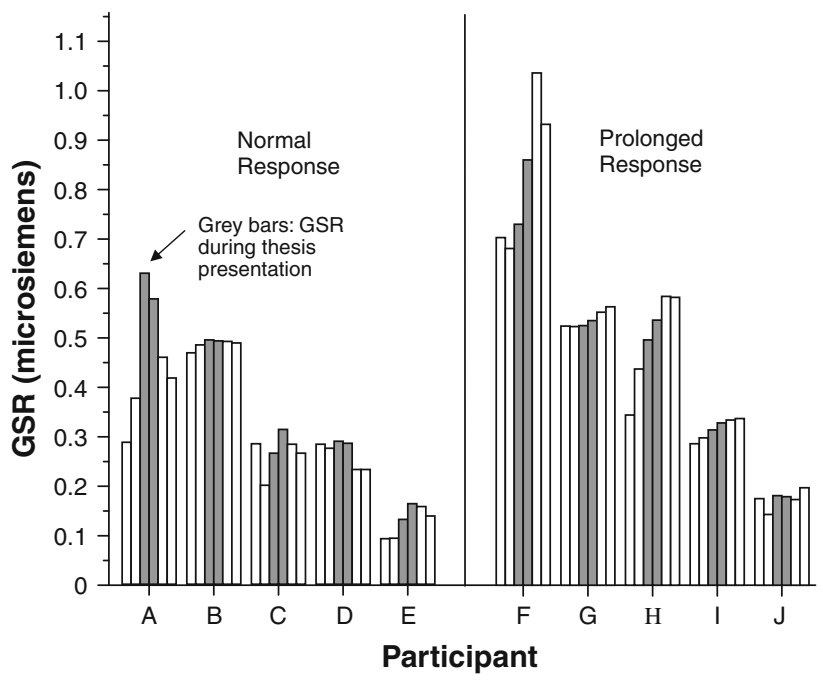

Fig. 1 Individual GSR response pattern (each block representing 5 min) before (white blocks) during (grey blocks) and after (white blocks) first thesis presentation

\section{Association of Response Pattern and Self-Confidence}

The normal pattern (1) vs. prolonged (2) SCL response pattern was significantly associated with self-confidence $(r=-.727, p<0.05)$.

Self-confidence (scale range 1-6) of the five participants in the prolonged response pattern group was 2.60, 3.20, $3.20,3.40$, and 3.40. Self-confidence in the normal response pattern group was 3.40, 3.60, 3.60, and 4.20. Highest values in the prolonged response pattern group equalled the lowest value in the normal response pattern group. The Mann-Whitney U-test showed ranks of selfconfidence to be significantly lower in the prolonged

Table 1 Kendall's tau rank correlations between study variables

\begin{tabular}{|c|c|c|c|c|c|c|c|c|c|c|}
\hline & Sex & Age & Self-confidence & Talk perf & SCL 1 & SCL 2 & SCL 3 & SCL 4 & SCL 5 & SCL 6 \\
\hline Age & .356 & & & & & & & & & \\
\hline Self-confidence & .119 & -.025 & & & & & & & & \\
\hline Talk performance & -.442 & .056 & -.280 & & & & & & & \\
\hline SCL 1 & .149 & -.330 & -.047 & -.158 & & & & & & \\
\hline SCL 2 & .149 & -.330 & -.047 & -.158 & $1.000(* *)$ & & & & & \\
\hline SCL 3 & .149 & -.189 & -.047 & -.158 & $.822(* *)$ & $.822(* *)$ & & & & \\
\hline SCL 4 & .224 & -.094 & .047 & -.158 & $.733(* *)$ & $.733(* *)$ & $.911(* *)$ & & & \\
\hline SCL 5 & .224 & -.189 & .000 & -.105 & $.867(* *)$ & $.867(* *)$ & $.778(* *)$ & $.867(* *)$ & & \\
\hline SCL 6 & .224 & -.189 & .000 & -.105 & $.867(* *)$ & $.867(* *)$ & $.778(* *)$ & $.867(* *)$ & & \\
\hline Normal/Prolonged SCL response $(1,2)$ & .000 & .158 & $-.727(*)$ & .318 & .328 & .328 & .268 & .268 & .388 & .388 \\
\hline
\end{tabular}

$\operatorname{Sex}(0=\mathrm{f}, 1=\mathrm{m})$

SCL 1 10-6 min before presentation starts, SCL $25 \mathrm{~min}$ before presentation starts until start, SCL 3 fist 5 min of presentation, SCL 4 6-10 min of presentation, $S C L 5$ fist $5 \mathrm{~min}$ after presentation ended, SCL $65-10 \mathrm{~min}$ after presentation ended

$* 0.05, * * 0.01$ (two-tailed) 
Table 2 Nonparametric trend test of GSR response pattern (Ferguson 1965)

\begin{tabular}{lccc}
\hline & \multicolumn{3}{c}{ Trend component } \\
\cline { 2 - 4 } & Monotone & Bitone & Tritone \\
\hline All participants $(\mathrm{N}=10)$ & & & \\
$\Sigma \mathrm{S}$ & 74 & -40 & -14 \\
Standard error of $\mathrm{S}$ & 16.773 & 15.866 & 16.773 \\
$z$ & 4.352 & -2.458 & -0.775 \\
$p$ & $<.001$ & .014 & .434 \\
Normal response $(n=5)$ & & & \\
$\Sigma \mathrm{S}$ & 57 & 0 & -7 \\
Standard error of $\mathrm{S}$ & 11.902 & 11.254 & 11.902 \\
$z$ & 4.70 & 0.00 & 0.50 \\
$p$ & $<.001$ & 1 & -0.617 \\
Prolonged response $(n=5)$ & & \\
$\Sigma \mathrm{S}$ & 17 & -40 & -7 \\
Standard error of S & 11.818 & 11.183 & 11.818 \\
$z$ & 1.354 & -3.487 & -0.508 \\
$p$ & .177 & $<.001$ & .610 \\
\hline
\end{tabular}

$\mathrm{S}=$ rank statistic (Kendall 1955), $z=$ normal deviate statistic (Ferguson 1965)

response group (Mann-Whitney $U=1, n_{1}=n_{2}=5$, $p<0.05$ two-tailed).

\section{Discussion}

Results showed momentary self-confidence to predict stress response to oral defence of a master thesis. Therefore selfconfidence appears, as expected, to be a resource for coping with such stressful situations as public speaking (Meier et al. 2008). A normal response reflects the ability to adapt to challenging situations by recovering quickly from physiological stress reactivity. In a broader context, selfconfidence as a resource should correspond to general selfefficacy that is strongly related to goal orientation and students' grade point average (Frese et al. 1987). Goal orientation includes more adequate coping, probably mediated by more task-specific self-efficacy, better strategies, better preparation, etc. (Frese and Zapf 1994). Self-confidence reflecting an internal locus of control and high selfefficacy has also been found to be a moderator of effective use of job control (Meier et al. 2008). Hence, stress prevention and intervention should tend to enhance self-confidence, e.g. by applying control in task fulfilment. Frese and Zapf (1994) point to control as an antecedent of control cognitions like self-confidence. 'Not having control implies that the goals and plans of work are outside the person working' (p. 295). Therefore, control in graduate students seems to play a central role and should be increased.
Limitations

The natural setting of the study accounts for the small sample size and replication seems necessary. In a replication study, rater reliability checks should be performed for the ratings of performance. Confidence ratings were made at the start of the presentation session for all participants. Hence, the time interval between collection of these readings and the start of the student's presentations varies by individual. In a replication study, the time interval should be standardized. On the other hand, the natural setting of the study is an advantage. Interpolation from study results to other contexts within higher education is more reliable than it would be in a laboratory setting. Currently we are not aware of validation studies that compare the Sensewear measurement of GSR with a gold standard of GSR measurement. The most influential bias in measurement should be motor activity. In this study, however, participants were in the same position during baseline, presentation, and after presentation, i.e. sitting on a chair. We therefore do not expect much bias from motor activity. Control of accelometric data measured in parallel did not change the results.

\section{Outlook}

This field study showed individual stress response during first presentation of the thesis to an audience to be associated with prior self-confidence. Individual differences in stressor-strain relations are a particularly interesting aspect of field research using ambulatory assessment on the association between work stressors and work strain (Berset et al. 2009; Elfering et al. 2005; Grebner et al. 2004). For instance, Totterdell et al. (2006), across a period of 26 weeks, showed the combination of high weekly work demands and low weekly job control had the most adverse effects in terms of strain on respondents who were comparably pessimistic. Field studies using SCL, however, have been rare until now. SCL measurement should be sensitive to emotional tension and its positive and negative aspects. Emotional tension may be adaptive or maladaptive in both nature and outcome (Rotenberg and Boucsein 1993). On the one hand, emotional tension serves to allocate resources to the complex task. On the other hand, it should not prevent the individual from continuing with his/ her goal-directed behaviour by distracting attention and resources from the task to the self (Semmer et al. 2007). More occupational field research in SCL stress response patterns seems promising in studying moderators of stress responses that may indicate coping with inadequate physiological cost and long-term decreased body resistance (Semmer et al. 2010).

Continuous recording of physiological data in natural contexts is still a technological challenge. SCL measurement 
in this field study is exemplary for small, unobtrusive and helpful instrumentation that is fast becoming a valid tool in work and organisational psychology (Klumb et al. 2009). Self-confidence has turned out to be a resource factor in public speaking stress of graduate students. Higher education should deliver adequate feedback, acknowledge good work, give support in difficult situations, teach skills including presentation skills, assign tasks that are challenging but possible, and help students to organise work efficiently to enhance self-confidence.

\section{References}

Apenburg, E. (1986). Befindlichkeitsbeschreibung als Methode der Beanspruchungsmessung. Untersuchungen zur Entwicklung und Validierung einer modifizierten Fassung der Eigenzustandsskala von Nitsch [Description of state as a method for measuring stress related to job demands: Studies related to the development and validation of a modified version of Nitsch's personal state scale]. Zeitschrift für Arbeits- und Organisationspsychologie, 30, 3-14.

Bachmann, N., Berta, D., Eggli, P., \& Hornung, R. (1999). Macht Studieren krank? [Does study make sick?] Berne: Hans Huber.

Backs, R. W., \& Boucsein, W. (Eds.). (2000). Engineering psychophysiology: Issues and application. Mahwah, NJ: Lawrence Erlbaum.

Bandura, A. (1997). Self-efficacy: The exercise of control. New York: Freeman.

Berset, M., Semmer, N. K., Elfering, A., Amstad, F., \& Jacobshagen, N. (2009). Work characteristics as predictors of physiological recovery on weekends. Scandinavian Journal of Work, Environment and Health, 35, 188-192.

Boucsein, W. (1992). Electrodermal activity. New York: Plenum.

Boucsein, W. (2001). Physiologische Grundlagen und Meßmethoden der dermalen Aktivität. In F. Rösler (Ed.), Enzyklopädie der Psychologie, Bereich Biologische Psychologie, Band 4: Grundlagen und Methoden der Psychophysiologie (S. 551-623). Göttingen: Hogrefe.

Boucsein, W. (2005). Electrodermal measurement. In N. Stanton, A. Hedge, K. Brookhuis, E. Salas, \& H. Hendrick (Eds.), Handbook of human factors and ergonomic methods (18-1-18-8). London: CRC Press.

Boucsein, W., Schaefer, F., \& Sommer, T. (2001). Electrodermal long-term monitoring in everyday life. In J. Fahrenberg \& M. Myrtek (Eds.), Progress in ambulatory assessment (S. 549-560). Göttingen: Hogrefe.

Boucsein, W., \& Wendt-Suhl, G. (1981). An experimental investigation of elements involved in the anticipation of public speaking. Archiv für Psychologie, 133, 1-8.

Brosschot, J. F., Pieper, S., \& Thayer, J. F. (2005). Expanding stress theory: Prolonged activitation and perseverative cognition. Psychoneuroendocrinology, 30, 1043-1049.

Croft, R. J., Gonsalvez, C. J., Gander, J., Lechem, L., \& Barry, R. J. (2004). Differential relations between heart rate and skin conductance, and public speaking anxiety. Journal of Behavior Therapy and Experimental Psychiatry, 35, 259-271.

Elfering, A., Grebner, S., Semmer, N. K., Kaiser-Freiburghaus, D., Lauper-Del Ponte, S., \& Witschi, I. (2005). Chronic job stressors and job control: Effects on event-related coping success and well-being. Journal of Occupational and Organizational Psychology, 78, 237-252.
Fahrenberg, J. (2006). Assessment in daily life. A review of computer-assisted methodologies and applications in psychology and psychophysiology (years 2000-2005). Retrieved April 14, 2009, from, http://ambulatory-assessment.org/index. php?id=32.

Fahrenberg, J., \& Wientjes, C. J. (2000). Recording methods in applied environments. In R. W. Backs \& W. Boucsein (Eds.), Engineering psychophysiology. Issues \& applications (pp. 111-138). London: Lawrence Erlbaum.

Ferguson, G. A. (1965). Nonparametric trend analysis. Montreal: McGill University Press.

Frankenhaeuser, M. (1991).The psychophysiology of sex differences as related to occupational status. In M. Frankenhaeuser, U. Lundberg, \& M. Chesney (Eds.), Woman, work, and health. Stress and opportunities (pp. 39-61). New York: Plenum Press.

Frese, M., Stewart, J., \& Hannover, B. (1987). Goal-orientation and planfulness: Action styles as personality concepts. Journal of Personality and Social Psychology, 52, 1182-1194.

Frese, M., \& Zapf, D. (1994). Action as the core of work psychology: A German approach. In H. C. Triandis, M. D. Dunnette, \& L. M. Hough (Eds.), Handbook of industrial and organizational psychology (Vol. 4, 2 edn.) (pp. 271-340). Palo Alto, CA: Consulting Psychology Press.

Gilkinson, H. (1942). Social fears as reported by students in college speech classes. Speech Monographs, 9, 141-160.

Grebner, S., Elfering, A., Semmer, N. K., Kaiser-Probst, C., \& Schlapbach, M. L. (2004). Stressful situations at work and in private life among young workers: An event sampling approach. Social Indicators Research, 67, 11-49.

Judge, T. A., Bono, J. E., \& Locke, E. A. (2000). Personality and job satisfaction: The mediating role of job characteristics. Journal of Applied Psychology, 85, 237-249.

Kallus, K. (1992). Beanspruchung und Ausgangszustand. In D. Frey, H. Keupp, E. D. Lantermann, R. K. Silbereisen, \& B. Weidenmann (Eds.), Fortschritte der psychologischen Forschung, Bd. 14. Weinheim: Beltz.

Kendall, M. G. (1955). Rank correlation methods (2nd ed.). London: Griffin.

Kirschbaum, C., Pirke, K.-M., \& Hellhammer, D. H. (1993). The 'Trier Social Stress Test'- a tool for investigating psychobiological stress responses in a laboratory setting. Neuropsychobiology, 28, 76-81.

Klumb, P., Elfering, A., \& Herre, C. (2009). Ambulatory assessment in I/O psychology: Fruitful examples and methodological issues. European Psychologist, 14, 120-131.

Lee, S. B., Hong, J. H., Lee, T. S., \& Ieee. (2007). Analysis of physical activities in wu-shu training. In 2007 annual international conference of the Ieee engineering in medicine and biology society, (Vol. 1-16, pp. 632-635). New York: Ieee.

McEwen, B. (1998). Protective and damaging effects of stress mediators. New England Journal of Medicine, 338, 171-179.

Meier, L. L., Semmer, N. K., Elfering, A., \& Jacobshagen, N. (2008). The double meaning of control: Three-way interactions between internal resources, job control, and stressors at work. Journal of Occupational Health Psychology, 13, 244-258.

Rotenberg, V. S., \& Boucsein, W. (1993). Adaptive versus maladaptive emotional tension. Genetic, Social, and General Psychology Monographs, 119, 209-232.

Schütte, M. (2009). Methods for measuring mental stress and strain. In C. M. Schlick (Ed.), Industrial engineering and ergonomics (pp. 395-411). Berlin: Springer.

Semmer, N., Grebner, S., \& Elfering, A. (2010). Psychische Kosten von Arbeit. Enzyklopädie der Psychologie. Band: Arbeitspsychologie (Bd. D-III-1, pp. 325-370). [Psychological costs of work]. In German 'Encyclopedia of Psychology', Volume: Work Psychology]. Göttingen: Hogrefe. 
Semmer, N. K., Jacobshagen, N., Meier, L. L., \& Elfering, A. (2007). Occupational stress research: The "stress-as-offence-to-self" perspective. In J. Houdmont \& S. McIntyre (Eds.), Occupational health psychology: European perspectives on research, education and practice (Vol. 2, pp. 43-60). Maia, Portugal: ISMAI Publishers.

Simpson, A., \& Turpin, G. (1983). A device for ambulatory skin conductance monitoring. Psychophysiology, 20, 225-229.

Totterdell, P., Wood, S., \& Wall, T. (2006). An intra-individual test of the demands-control model: A weekly diary study of psychological strain in portfolio workers. Journal of Occupational and Organizational Psychology, 79, 63-84.

Turpin, G., Shine, P., \& Lader, H. (1983). Ambulatory electrodermal monitoring effects of ambient temperature, general activity, electrolyte media, and length of recording. Psychophysiology, 20, 219-224.

White, B. C., \& Charles, P. (1983). Telemetric skin conductance with computer interface. Psychophysiology, 20, 597-599. 